\title{
Successful treatment of acute B lymphoblastic leukemia relapse in the skin and testicle by anti-CD19 CAR-T with IL-6 knocking down: a case report
}

Ze-Fa Liu ${ }^{1 \dagger}$, Li-Yun Chen ${ }^{2,3+}$, Jin Wang ${ }^{4}$, Li-qing Kang ${ }^{5}$, Hua Tang ${ }^{1}$, Yao Zhou ${ }^{1}$, Hai-Xia Zhou ${ }^{2,3}$, Ai-Ning Sun ${ }^{2,3}$, De-Pei $\mathrm{Wu}^{2,3^{*}}$ and Sheng-Li Xue $2,3^{*}$ iD

\begin{abstract}
Background: Extramedullary relapse is an important cause of treatment failure among patients with acute lymphoblastic leukemia (ALL). This type of relapse is commonly observed in the central nervous system, while it is rare in the testicles and skin. Chimeric antigen receptor-modified T cell (CAR-T) therapy targeting CD19 has shown to be a beneficial treatment approach for relapsed/refractory B cell acute lymphoblasticleukemia (r/r B-ALL). Yet, few studies have reported data regarding the treatment of extramedullary B-ALL relapse, especially both in skin and testicle, with CAR-T therapy.
\end{abstract}

Case presentation: Here we reported a single case of a patient with relapsed B-ALL in skin and testicle who was successfully treated by the shRNA-IL6-modified anti-CD19 CAR-T(sSCAR-T-19) therapy. A 29-year-old man with relapsed B-ALL in skin and testicle was enrolled in clinal trial involving the shRNA-IL6-modified anti-CD19 CART(ssCAR-T-19) therapy (ClinicalTrials.gov number, NCT03919240). The patient had toxicity consistent with the grade 1 cytokine release syndrome.

Conclusions: SSCART-19 therapy may be used to effectively eliminate infiltrating leukemia cells in the skin and testicle with mild toxicity, which could be a much safer approach to bridge allo-HSCT, thus further improving the patient's outcome.

Trial registration: ClinicalTrials.gov number, NCT03919240, Registered 18 April 2019, retrospectively registered.

Keywords: Acute lymphoblastic leukemia, Extramedullary relapse, Chimeric antigen receptor-modified T cell therapy, IL-6 knocking down

\section{Introduction}

Extramedullary relapse, which is not a frequent recurrence of leukemia occurring in sites other than the bone marrow, is an important cause of treatment failure among

\footnotetext{
*Correspondence: wudepei@suda.edu.cn; slxue@suda.edu.cn

${ }^{+}$Ze-Fa Liu and Li-Yun Chen contributed equally to this work.

${ }^{2}$ Jiangsu Institute of Hematology, The First Affiliated Hospital of Soochow University, Shizi street 188, Suzhou 215006, China

Full list of author information is available at the end of the article
}

patients with acute lymphoblastic leukemia (ALL) [1]. One-third of all extramedullary ALL relapses are reported in the central nervous system [2], while the relapses in testicle and skin are relatively uncommon $[3,4]$.

Chemotherapy is the first treatment of choice for patients with extramedullary ALL relapse followed by radiotherapy. Over the last few years, chimeric antigen receptor-modified $\mathrm{T}$ cell (CAR- $\mathrm{T})$ therapy targeting CD19 has shown to be a beneficial treatment approach

(c) The Author(s). 2020 Open Access This article is licensed under a Creative Commons Attribution 4.0 International License, which permits use, sharing, adaptation, distribution and reproduction in any medium or format, as long as you give appropriate credit to the original author(s) and the source, provide a link to the Creative Commons licence, and indicate if changes were made. The images or other third party material in this article are included in the article's Creative Commons licence, unless indicated otherwise in a credit line to the material. If material is not included in the article's Creative Commons licence and your intended use is not permitted by statutory regulation or exceeds the permitted use, you will need to obtain permission directly from the copyright holder. To view a copy of this licence, visit http://creativecommons.org/licenses/by/4.0/ The Creative Commons Public Domain Dedication waiver (http://creativecommons.org/publicdomain/zero/1.0/) applies to the data made available in this article, unless otherwise stated in a credit line to the data. 
for relapsed/refractory B cell acute lymphoblastic leukemia ( $r / r$ B-ALL) $[5,6]$. Yet, only very few studies have reported data regarding the treatment of extramedullary B-ALL relapse in skin and testicle with CAR-T therapy. Here we reported a single case of a patient with relapsed B-ALL isolatedly in skin and testicle with bone marrow remission who was successfully treated by the shRNA-IL6-modified anti-CD19 CAR-T (ssCAR-T-19) therapy. The feasibility and safety of a ssCAR-T-19 treatment are also discussed.

\section{Case presentation}

A 29-year-old man, who presented with skin nodules and swollen testicle, was initially admitted to Shanghai Renji Hospital. Physical examination showed multiple red nodules in the skin and the swollen left testicle. Peripheral blood counts showed white blood cells total count of $7.0 \times 10^{9} / \mathrm{L}$, hemoglobin levels of $113 \mathrm{~g} / \mathrm{L}$, and platelets total count of $87 \times 10^{9} / \mathrm{L}$. Skin biopsy indicated B lymphocytic malignancies. Consequently, bone marrow aspiration analysis by morphology, immunophenotyping, cytogenetics, and molecular genetics suggested B-ALL. Moreover, the ultrasound examination confirmed the swollen left testicle. Finally, the patient was diagnosed with B-ALL, accompanied by extramedullary infiltration in the skin and testicle.

After induction therapy with VDLP (vincristine+daunorubicin+ L-asparaginase +prednisone), skin nodules disappeared, testes shrank, and complete remission was achieved, which was confirmed by bone marrow aspiration examination. However, after 3 cycles of consolidation treatment, the skin nodules (Fig. 1a, c, d) and the swelling of the scrotum reappeared (Fig. 2c).

Subsequently, the patient was referred to the hematology department of the First Affiliated Hospital of Soochow University. Bone marrow aspiration analysis by morphology, flow cytometry, and the next-generation sequencing showed no relapse. Flow cytometry analysis of skin biopsy showed $93.1 \%$ of blast proportion with immature B cell immunophenotyping profile (CD10+:
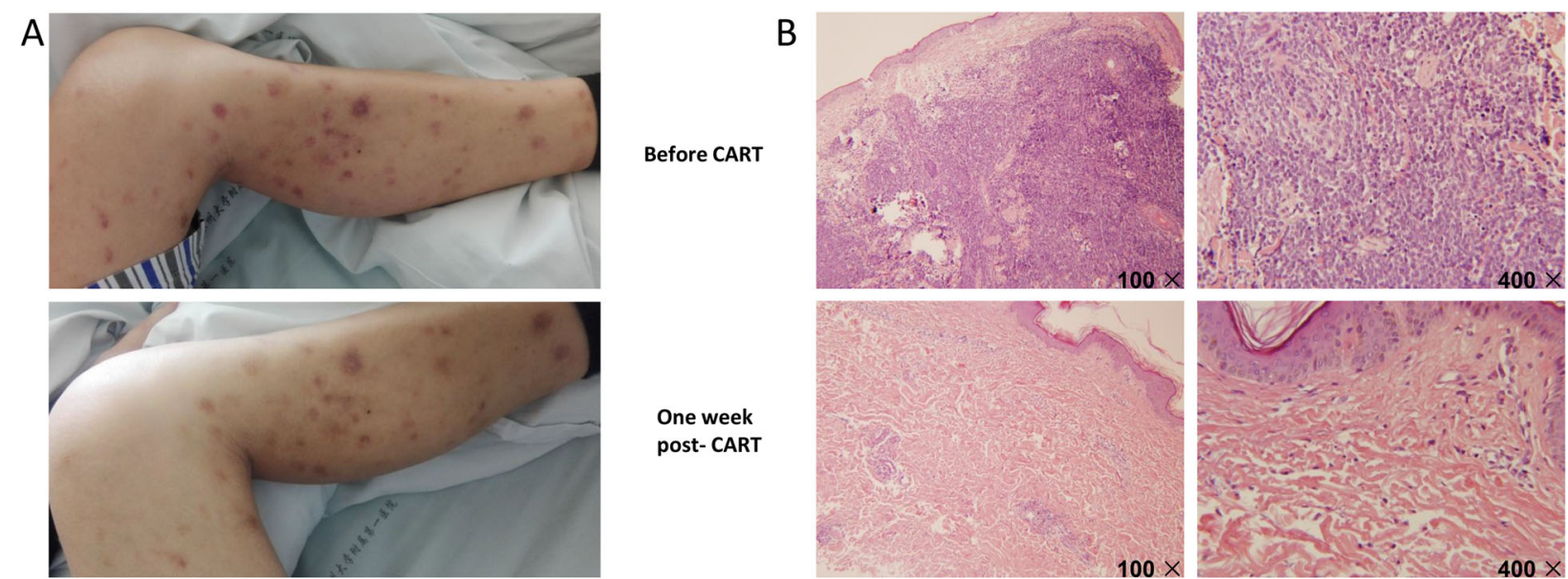

$100 \times$

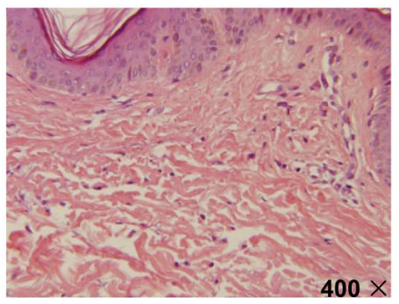

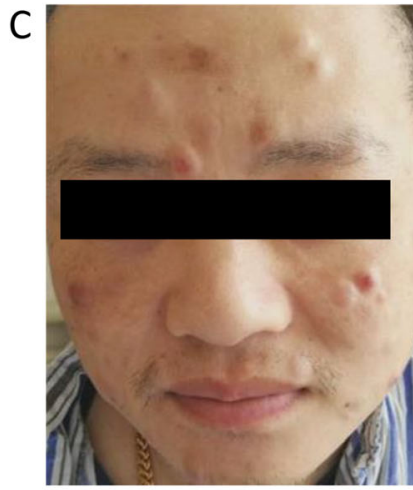

Before CART

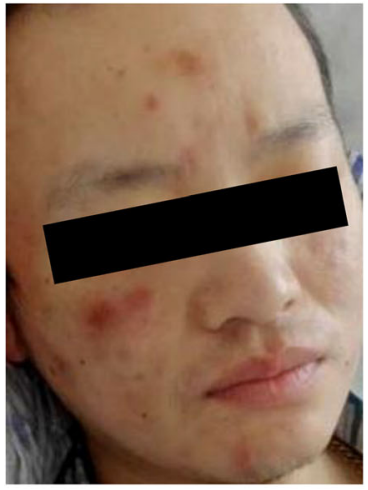

One week post- CART

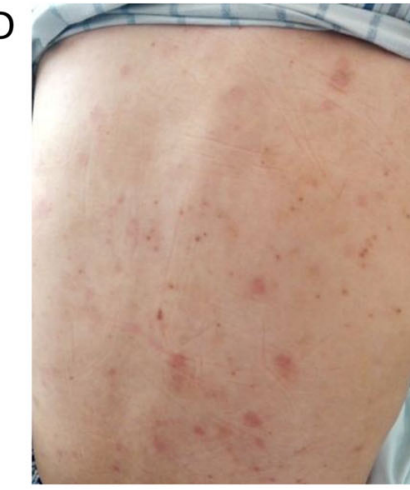

Before CART

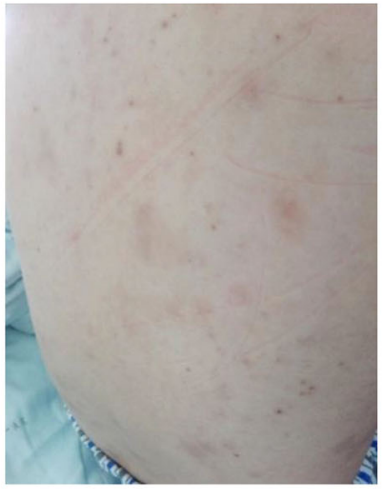

One week post- CART

Fig. 1 Changes in the patient's skin before and after ssCART-19 cells infusion. a, Left lower limb skin. b, Skin biopsy from left lower limb and staining by HE. c, Facial skin. d, Back skin 


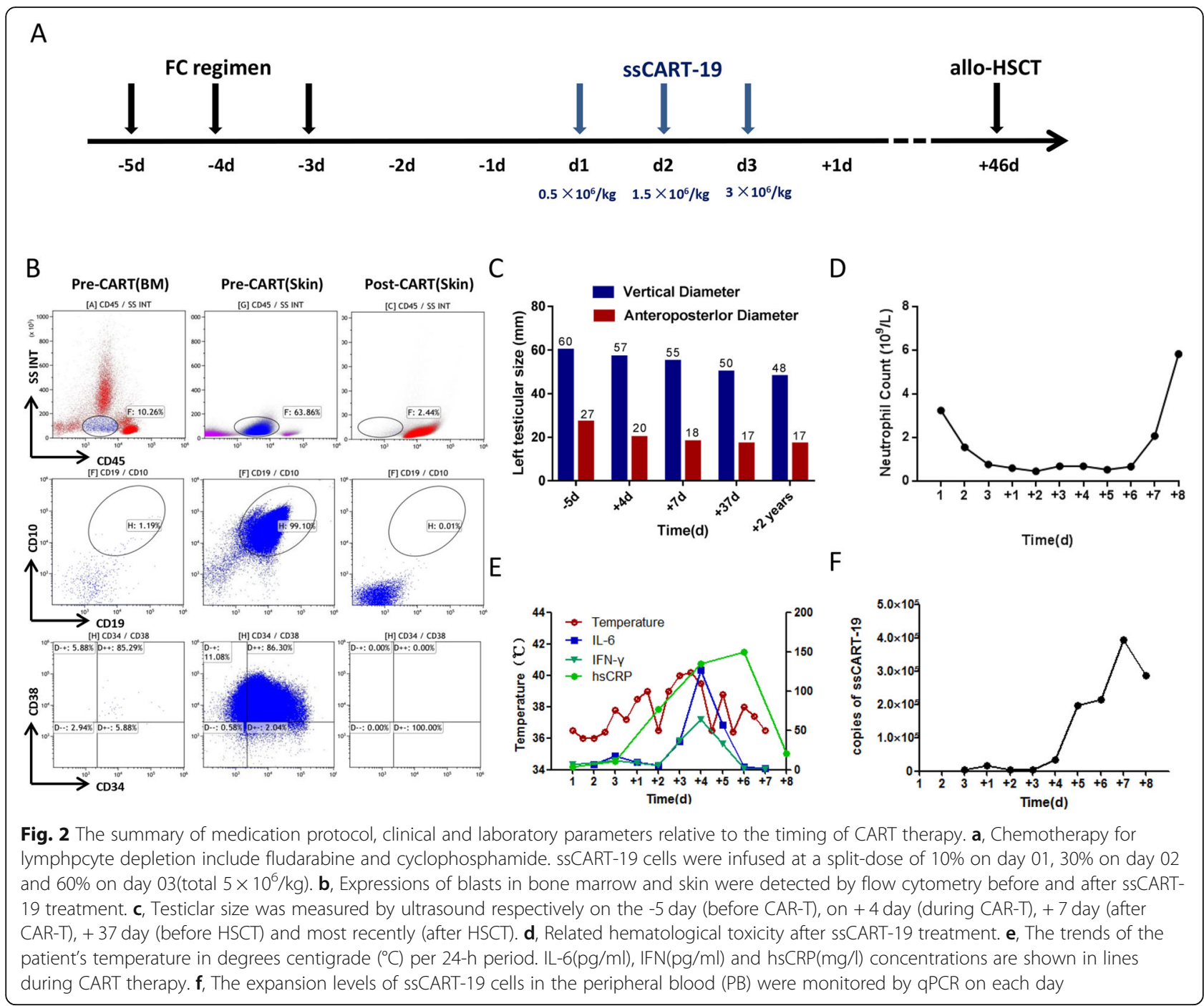

99.9\%, CD22+: 99.8\%, CD19+: 90.9\%, CD20 + -: 97.9\%, CD38+: 99\%, CD34 +-: 73.9\%)(Fig. 2b). The pathology of skin biopsy was consistent with B lymphoblastic lymphoma/ALL infiltration (Fig. 1b). Considering the poor responses in skin and testicle to conventional chemotherapy, the patient was enrolled in an anti-CD19 CAR-T clinical trial (ClinicalTrials.gov number, NCT03919240).

During the clinical trial, the $\mathrm{T}$ cells from the patient were purified from the blood by gradient centrifugation using Lymphoprep ${ }^{\mathrm{Tm}}$ (Oriental Hua Hui, Beijing, China). Cells were then enriched using anti-CD3 magnetic beads (Miltenyi Biotec, Bergisch Gladbach, Germany). CD3 + T cells were stimulated with anti-CD3/CD28 (Miltenyi Biotec) monoclonal antibodies for $24 \mathrm{~h}$ and then transduced with recombinant lentiviral vectors encoding the CD19-specific CAR, and comprising an anti-CD19 single-chain variable fragment $(\mathrm{scFv}), 4-1 \mathrm{BB}$ costimulatory moiety, CD3-〈activation domain, and IL-6 shRNA element, all manufactured by UniCar Therapy Ltd. CAR-T cells were cultured in AIM-V media (Gibco, Grand Island, NY, USA) supplemented with 10\% autologous serum, $100 \mathrm{IU} / \mathrm{ml}$ IL-2 (Peprotech, Rocky Hill, USA), $5 \mathrm{ng} / \mathrm{ml}$ IL-7(Peprotech), and $5 \mathrm{ng} / \mathrm{ml}$ IL15(Peprotech) for 12 days [7]. Before CAR-T cell infusion, the patient received lymphodepleting chemotherapy for 3 days with Fludarabine $30 \mathrm{mg} / \mathrm{m}^{2} /$ day and Cyclophosphamide $250 \mathrm{mg} / \mathrm{m}^{2} /$ day. Infection-related examinations including procalcitonin, spot test using $\mathrm{T}$ lymphocytes, 1,3 - $\beta$ glucan test, galactomannan test and chest CT scanning, were performed and showed negative results. Two days after conditioning, the patient received SSCART-19 cells infusion at a total dose of $5 \times$ $10^{6}$ cells/kilogram for 3 consecutive days (Fig. 2a). Four days after infusion, the patient suffered from lower swelling in skin nodules and left testicle, accompanied by high fever. However, 1 week after infusion the patient's skin nodules disappeared, and only the 
chromatosis remained (Fig. 1a, c, d). Biopsy showed few lymphocytes infiltration but no leukemia cells, which was confirmed by flow cytometry (Fig. 2b). Besides, the ultrasound examination revealed shirked testicles (Fig. 2c). Forty-six days after ssCART-19 therapy, the patient underwent allogeneic hematopoietic stem cell transplantation (allo-HSCT) from a matched unrelated donor, and at the moment is in complete remission. Until now he is followed up for 2 years and 1 month after HSCT with no signs of relapse in bone marrow, skin or testicles.

During the treatment, the indicators of cytokine release syndrome (CRS) and cytokine release encephalopathy syndrome (CRES) were comprehensively monitored. The levels of IL-6, IFN- $\gamma$ and hsCRP were elevated following ssCART-19 cells infusion; they were consistent with the changes in body temperature, and declined to basal level spontaneously in 1 week (Fig. 2e). CRS in grade 1 was considered only due to discomfort related to fevers (Fig. 2e) and no CRES was detected. The proliferation of ssCART-19 cells detected by the real-time quantitative PCR was noted on day +6 , and sustained on a high level for several days (Fig. 2f). The data of blood biochemical, BNP, troponin and D-dimer turned out to be normal. The patient had granulocytopenia without thrombocytopenia or anemia after infusion (Fig. 2d). The granulocytes recovered on day +8 .

\section{Discussion}

The extramedullary ALL relapses in skin and testicle are rare. What's more important, thus far there are no standard management protocols for patients with this rare isolated extramedullary relapse that may lead to dismal outcomes.

CAR-T therapy is a novel therapeutic strategy for $r / r$ B-ALL patients [8-10]. CAR-T cells can migrate into the leukemia cell sanctuary, such as cerebrospinal fluid by overcoming the blood-brain barrier (BBB), which might be an important approach for solving the sanctuary leukemia problems with traditional chemical agents [11]. He et al reported anti-CD19 CAR-T as a feasible and safe treatment against central nervous system leukemia after intrathecal chemotherapy in adults with $\mathrm{r} / \mathrm{r}$ B-ALL [12]. Furthermore, Dai and colleagues reported the beneficial effect of CAR-T infusion on patients with active CNSL [13]. All these data suggest that CAR-T cells can enter the central nervous system and eliminate leukemia cells. Thus, it is reasonable to postulate that CAR-T cells could use the same mechanism to target leukemia cells in other parts of the body, such as testicles and skin. Here we reported a single case with relapsed B-ALL in skin and testicle, which was successfully treated by the shRNA-IL6-modified anti-CD19 CAR-T (Fig. 2c).
Wang and colleagues reported that extramedullary ALL relapse in the cervix manifesting as a solid mass after allo-HSCT could be completely removed by CAR T-cell therapy [14], thus suggesting that CAR-T cells possess a highly penetrating and eradicating ability when encountering extramedullary leukemia mass. Due to a large number of capillaries, CAR-T cells should be able to infiltrate the skin and reach leukemia cells acting as subcutaneous nodules facilitated by the capillary transportation and working more efficiently, which was supported by the present case where skin nodules were significantly diminished (Fig.1a, c, d). Of note, a high level of CAR-T cells copies was detected in the peripheral blood during CAR-T treatment. This further demonstrated that vigorous CAR-T cells might eliminate extramedullary B-ALL relapse.

The severe CRS and CRES are still the main safety issues of CAR-T therapy in clinical management [15] caused by the rapid elevation of multiple cytokines, mainly IL-6 from activated CAR-T cells, and mononuclear cells, such as macrophage cells and DC cells. The activated CAR-T cells, stimulated by specific targeting cells, have an essential role in imitating CRS and CRES development. Since anti-IL-6 receptor monoclonal antibody, the standard procedure in the clinical management of severe CRS, could not penetrate BBB and limit the treatment of CRES, we generated a CAR construction with IL-6 shRNA. Our previous study (results not published) showed that the suppression of IL-6 gene expression in CAR-T cells significantly decreased the IL-6 release from monocyte in vitro, and potentially reduced the chance of severe CRS and CRES in vivo. Wang et al used conventional CAR-T cells to treat extramedullary relapse in the cervix and reported a low-grade CRS but severe CRES. Urinary incontinence was observed, which was likely due to neurotoxicity side effects from CAR-T therapy. Nevertheless, in our case, ssCART-19cells were applied, and no CRES was observed, thus suggesting that ssCART-19could be an alternative choice to avoid the side effects of conventional CAR-T therapy in special tissue such as CNS and testicle.

Unfortunately, the CAR-T cell copies were not detected in testicle and skin due to the ethical problem of taking the sample. So the infiltration efficiency of CAR$\mathrm{T}$ cells from the blood into these extramedullary sites and proliferation dynamic in these sites remain unclear.

\section{Conclusions}

ssCART-19 therapy may be used to effectively eliminate infiltrating leukemia cells in the skin and testicle with mild toxicity, which could be a much safer approach to bridge allo-HSCT, thus further improving the patient's outcome. 


\section{Abbreviations}

ALL: Acute lymphoblastic leukemia; CAR-T: Chimeric antigen receptormodified T cell; r/r B-ALL: relapsed/refractoryB cell acute lymphoblastic leukemia; sSCAR-T-19: shRNA-IL6-modified anti-CD19CAR-T; CRS: Cytokine release syndrome; CRES: Cytokine release encephalopathy syndrome; BBB: Blood-brain barrier; Allo-HSCT: Allologous hematopoietic stem cell transplantation; DC: Dendritic cells; CNS: Central nervous system

\section{Acknowledgements}

The authors would like to thank all members of the study team, the patient and their family, and Shanghai Unicar-Therapy Biomed Phamaceutical Technology CO, LTD.

\section{Authors' contributions}

SIX, AnS and DpW conceived and design the study. ZfL, LyC and SIX analyzed and interpreted the data. ZfL, LyC and SIX wrote the manuscript. DpW, HxZ, JW and AnS provided the study materials or patients. LqK, HT and YZ performed the experiments. All authors read and approved the final manuscript.

\section{Funding}

This work was supported by the National Natural Science Foundation of China (grant No. 81970138, 81873449, 81570138), Jiangsu Province "333" project (grant No. BRA2018391), Jiangsu Province Medical Youth Talent Program (grant No. QNRC2016719), a C class sponsored project from Jiangsu Provincial Six Talent Peaks (grant No. 2016-WSN-123) and Gusu Key Medical Talent Program (grant No. GSWS2019007).

\section{Availability of data and materials}

The datasets supporting the conclusions are included within this article.

\section{Ethics approval and consent to participate}

The research protocol referenced in this manuscript abided by Declaration of Helsinki and has been approved by the Ethics Committee of the First Affiliated Hospital of Soochow University.

The patient has consented to the submission of the case report.

\section{Competing interests}

The authors have no conflicts of interest to disclose.

\section{Author details}

'Department of Hematology, People's Hospital of Xinghua, Taizhou, Jiangsu Province, China. ${ }^{2}$ Jiangsu Institute of Hematology, The First Affiliated Hospital of Soochow University, Shizi street 188, Suzhou 215006, China. ${ }^{3}$ Institute of Blood and Marrow Transplantation, Collaborative Innovation Center of Hematology, Soochow University, Suzhou, China. ${ }^{4}$ Faculty of Nursing, Suzhou Vocational Health College, Suzhou, China. ${ }^{5}$ Shanghai Unicar-Therapy Biomed Phamaceutical Technology CO, LTD, Shanghai, China.

Received: 29 January 2020 Accepted: 28 April 2020

Published online: 06 May 2020

\section{References}

1. Gaudichon J, Jakobczyk H, Debaize L, Cousin E, Galibert MD, Troadec MB, et al. Mechanisms of extramedullary relapse in acute lymphoblastic leukemia: reconciling biological concepts and clinical issues. Blood Rev. 2019;36:40-56

2. Gao RW, Dusenbery KE, Cao Q, Smith AR, Yuan J. Augmenting Total body irradiation with a cranial boost before stem cell transplantation protects against post-transplant central nervous system relapse in acute lymphoblastic leukemia. Biol Blood Marrow Transplant. 2018;24:501-6.

3. Weng J, Lai P, Qin L, Lai Y, Jiang Z, Luo C, et al. A novel generation 1928zT2 CAR T cells induce remission in extramedullary relapse of acute lymphoblastic leukemia. J Hematol Oncol. 2018;11(1):25.

4. Bertamini L, Nanni J, Marconi G, Abbenante M, Robustelli V, Bacci F, et al. Inotuzumab ozogamicin is effective in relapsed/refractory extramedullary B acute lymphoblastic leukemia. BMC Cancer. 2018;18(1):1117.

5. Shadman M, Gauthier J, Hay KA, Voutsinas JM, Milano F, Li A, et al. Safety of allogeneic hematopoietic cell transplant in adults after CD19-targeted CAR T-cell therapy. Blood Adv. 2019;3(20):3062-9.
6. Wei G, Hu Y, Pu C, Yu J, Luo Y, Shi J, et al. CD19 targeted CAR-T therapy versus chemotherapy in re-induction treatment of refractory/relapsed acute lymphoblastic leukemia: results of a case-controlled study. Ann Hematol. 2018;97(5):781-9.

7. Li C, Zhang Y, Zhang C, Chen J, Lou X, Chen X, et al. Comparation of CART19 and autologous stem-cell transplantation for refractory/relapsed non-Hodgkin's lymphoma. JCl Insight. 2019;23:5.

8. Mohty M, Gautier J, Malard F, Aljurf M, Bazarbachi A, Chabannon C, et al. CD19 chimeric antigen receptor-T cells in B-cell leukemia and lymphoma: current status and perspectives. Leukemia. 2019;33:2767-78.

9. Jiang H, Li C, Yin P, Guo T, Liu L, Xia L, et al. Anti-CD19 chimeric antigen receptor-modified T-cell therapy bridging to allogeneic hematopoietic stem cell transplantation for relapsed/refractory B-cell acute lymphoblastic leukemia: an open-label pragmatic clinical trial. Am J Hematol. 2019;94(10): $1113-22$.

10. Ali S, Kjeken R, Niederlaender C, Markey G, Saunders TS, Opsata M, et al. The European medicines agency review of Kymriah (Tisagenlecleucel) for the treatment of acute lymphoblastic leukemia and diffuse large B-cell lymphoma. Oncologist. 2019;25:e321-7.

11. Grupp SA, Kalos M, Barrett D, Aplenc R, Porter DL, Rheingold SR, et al. Chimeric antigen receptor-modified $\mathrm{T}$ cells for acute lymphoid leukemia. N Engl J Med. 2013;368(16):1509-18.

12. He X, Xiao X, Li Q, Jiang Y, Cao Y, Sun R, et al. Anti-CD19 CAR-T as a feasible and safe treatment against central nervous system leukemia after intrathecal chemotherapy in adults with relapsed or refractory B-ALL. Leukemia. 2019:33(8):2102-4.

13. Dai H, Zhang W, Li X, Han Q, Guo Y, Zhang Y, et al. Tolerance and efficacy of autologous or donor-derived T cells expressing CD19 chimeric antigen receptors in adult B-ALL with extramedullary leukemia. Oncoimmunology. 2015;4(11):e1027469.

14. Wang D, Shi R, Wang Q, Li J. Extramedullary relapse of acute lymphoblastic leukemia after allogeneic hematopoietic stem cell transplantation treated by CAR T-cell therapy: a case report. Onco Targets Ther. 2018;11:6327-32.

15. Hay KA. Cytokine release syndrome and neurotoxicity after CD19 chimeric antigen receptor-modified (CAR-) T cell therapy. Br J Haematol. 2018;183: $364-74$.

\section{Publisher's Note}

Springer Nature remains neutral with regard to jurisdictional claims in published maps and institutional affiliations.

\section{Ready to submit your research? Choose BMC and benefit from:}

- fast, convenient online submission

- thorough peer review by experienced researchers in your field

- rapid publication on acceptance

- support for research data, including large and complex data types

- gold Open Access which fosters wider collaboration and increased citations

- maximum visibility for your research: over $100 \mathrm{M}$ website views per year

At BMC, research is always in progress.

Learn more biomedcentral.com/submissions 